\title{
Campeonato Mundial de Fútbol de las Llanuras
}

\section{World Plains Soccer Championship}

\author{
Eugenio Matijasevic • Bogotá, D.C. (Colombia)
}

El 14 de febrero de 2007, en el estadio Mario Mercado Vaca Guzmán de Potosí, Bolivia, se enfrentaron en el marco de la Copa Libertadores de América los equipos de fútbol Flamengo de Brasil y Real Potosí de Bolivia. A pocos minutos de comenzar el partido los jugadores del Flamengo estaban exhaustos, debían descansar después de correr escasos 30 metros y algunos necesitaron oxígeno antes de poder retornar al campo de juego. Los jugadores de casa, entre tanto, se sentían bastante cómodos y jugaban relajados, sin más cansancio que el habitual en los momentos más críticos de un partido. A pesar de ello, los de casa no lograron remontar el marcador y el encuentro terminó con empate a 2 goles (1). El 18 de abril del mismo año, en el partido de ida para el Real Potosí, jugado en el estadio Maracaná de Rio de Janeiro, el Flamengo se impuso 1 a 0 al Real Potosí (2).

El Maracaná, situado a 18 metros sobre el nivel del mar (msnm), es la sede oficial del Flamengo (3) y del Fluminense Football Club. El estadio Mario Mercado, que cambiaría su nombre en años posteriores por el de Víctor Agustín Ugarte (4), situado a $3895 \mathrm{msnm}$, es uno de los estadios de fútbol a mayor altura en el mundo (5) y es la sede del Real Potosí (6). En lo que sigue, me he basado para los nombres de los estadios y de los equipos en la información suministrada por la página de la red World Stadiums (7) y para la altura de cada estadio me he basado en la herramienta de la red Elevationmap (8).

Después del partido jugado en Potosí, los directivos del Flamengo, apoyados por los directivos de otros equipos brasileños e incluso de algunos argentinos, declararon que, dadas las condiciones "antideportivas e inhumanas" en las que se había desarrollado el encuentro, no volverían a jugar en la altura y enviaron de manera oficial un reclamo a la Fédération Internationale de Football Association (FIFA), el ente regulador del fútbol profesional de todo el orbe (9).

El 28 de mayo de 2007 los noticieros de América Latina y del mundo repitieron hasta el cansancio la noticia deportiva que más daría qué hablar en el ámbito deportivo en los 12 meses siguientes: el Comité Ejecutivo de la FIFA, con base en una recomendación de los miembros de su Comité de Medicina Deportiva (FIFA Sports Medical Committee), a quienes les había sido remitida la queja presentada por el Flamengo, había prohibido a partir de la fecha la realización de partidos de fútbol de nivel internacional en estadios situados a más de 2500 msnm (10). La decisión se debía, adujeron los directivos de la FIFA, al interés del cuerpo rector por la salud de los deportistas y, además, para evitar cualquier posible "distorsión" en el espíritu de la competencia futbolística, en especial en lo concerniente a la imparcialidad de los encuentros (11).

La prohibición de la FIFA con respecto a los partidos internacionales no afectaba ningún estadio en Europa ni en Oceanía, pues en ninguno de estos dos continentes hay estadios a tales alturas. Tampoco afectaba estadios en Asia ni en África, pues, dada la reglamentación de la FIFA con respecto a las condiciones mínimas de un estadio y de una ciudad para albergar un encuentro de fútbol internacional (terreno de juego, número de asientos, aeropuerto, transporte, comunicaciones, disponibilidad hotelera e incluso iluminación del estadio) (12), los pequeños estadios de Nepal, Bután, la meseta Tibetana, Yemen, Afganistán, Eritrea y Etiopía situados por encima de 2500 msnm, nunca serían el escenario de un partido internacional, sobre todo porque ninguno contaba con la po-
Dr. Eugenio Matijasevic: Editor General Acta Médica Colombiana. Bogotá, D.C. (Colombia). E-mail: eugenio.matijasevic@gmail.com Recibido: 14/XI/2017 Aceptado: 15/XI/2017 
sibilidad de acomodar como mínimo 30000 espectadores sentados. En América del Norte la medida afectaba sólo al estadio Nemesio Díez de Toluca, México, a 2683 msnm.

En los países de América del Sur cuyas asociaciones nacionales de fútbol se encuentran vinculadas a la FIFA a través de la Confederación Sudamericana de Fútbol (CONMEBOL), la directriz afectaba nada menos que a los estadios de las capitales de Bolivia, Ecuador y Colombia, así como a numerosos estadios de ciudades principales de los tres mencionados países y de Perú, que cumplían los requisitos de la FIFA para la realización de encuentros internacionales de fútbol. El estadio a mayor altitud en Chile, el estadio Zorros del Desierto, situado en Calama, no cumplía para la época con los requerimientos de la FIFA para albergar un encuentro internacional y se encuentra localizado a $2276 \mathrm{msnm}$, así que, incluso si para la época hubiese sido reacondicionado para cumplir con los requisitos, no habría quedado cobijado por la prohibición (13). En Argentina, el otro de los países Andinos, y en Venezuela, Paraguay, Uruguay y Brasil, los países sudamericanos no andinos, la medida no afectaba ningún estadio que pudiese servir de escenario a un encuentro internacional. Guyana y Surinam, los otros países suramericanos, pertenecen a The Confederation of North, Central America and Caribbean Association (CONCACAF), no a la CONMEBOL, y no tienen estadios situados en la altura (no hay estadio en el tepuy Roraima, el punto más alto de Guyana a $2810 \mathrm{msnm}$ ). La Guyana Francesa, aunque en territorio suramericano, es un Departamento de Ultramar de la República Francesa (14) y sus futbolistas juegan en L'équipe de France de Football.

En La Paz quedaban vetados como escenarios de encuentros internacionales el estadio Hernando Siles, a $3598 \mathrm{msnm}$ (sede de los equipos Selección de Fútbol de Bolivia, Bolivar y The Strongest) y el estadio Rafael Mendoza Castellón, situado a $3504 \mathrm{msnm}$ (propiedad del equipo The Strongest).

En Quito quedaban excluidos el estadio Olímpico Atahualpa, situado a $2779 \mathrm{msnm}$ (sede de los equipos Selección de Fútbol de Ecuador, Deportivo Quito, El Nacional y Universidad Católica), y el estadio Casa Blanca (también llamado Estadio de Liga Deportiva Universitaria), situado a 2734 msnm (sede del equipo Liga Deportiva Universitaria).

En Bogotá se vería afectado el estadio El Campín, también conocido como estadio Nemesio Camacho (sede de los equipos Club Independiente Santa Fe y Millonarios Fútbol Club), pero los directivos de la Federación Colombiana de Fútbol aseguraron que, aunque la altura media de la ciudad se estimaba en $2640 \mathrm{msnm}$, El Campín estaría a $2470 \mathrm{msnm}$, por lo que, por 30 metros, escaparía a la medida adoptada por la FIFA. Albergaban la esperanza de que la Selección de Fútbol de Colombia pudiese jugar a veces en la capital del país (la sede oficial de la Selección es, desde 1989, el estadio Metropolitano Roberto Meléndez. de Barranquilla, situado a 54 msnm) (15), y que Bogotá conservase además la posibilidad de ser la sede de otros encuentros internacionales. Sin embargo, una medición oficial dirigida a zanjar cualquier duda realizada por el Instituto Geográfico Agustín Codazzi, institución de la República de Colombia a cargo de "producir el mapa oficial y la cartografía básica de Colombia, realizar las mediciones geográficas y catastrales, realizar el inventario de las características de los suelos y coordinar la Infraestructura Colombiana de Datos Espaciales" (16), determinó que el campo de juego de El Campín se encuentra a 2552.62 msnm, por lo que dicho estadio sí se vería cobijado por la determinación de la FIFA (17).

La reacción no se hizo esperar: en cada uno de los países afectados por la medida, desde el menos conspicuo de los ciudadanos de a pie hasta el presidente de la república, pasando por los miembros de las "barras bravas", los comentaristas deportivos, los editorialistas de los diarios y los directivos de la CONMEBOL, todo el mundo se sintió con derecho a opinar y se refirió a la medida rechazándola. Al parecer, sólo Sepp Blatter, presidente de la FIFA, su secretario general, Jerôme Valckem, y algunos allegados a su círculo más íntimo en dicho organismo y en el Comité de Medicina Deportiva, apoyaban la prohibición. Los gobernantes se sintieron llamados a ejercer su poder en pro de no permitir que a sus pueblos se les quitara parte del circo (para no hablar del pan que ya de por sí venía escaso, por otras razones, desde siglos atrás).

El 30 de mayo de 2017 Evo Morales, presidente de Bolivia, se sumó con sus ministros a un partido de fútbol callejero para protestar contra la prohibición de la FIFA con la intención de demostrar que, si él y sus ministros podían jugar fútbol por encima de $2500 \mathrm{msnm}$, no había motivos para afirmar que la flor y nata de los jugadores del mundo no pudiesen hacerlo también (18). "Si los países de las alturas están eliminados [de los partidos de la fase clasificatoria para el campeonato mundial de fútbol], los próximos campeones ya no serán mundiales, sino sólo de las llanuras" ironizó Morales frente a los medios de comunicación (19).

El 15 de junio de 2007, reunidos en Paraguay, los directivos de las federaciones de fútbol de los países sudamericanos representados en la CONMEBOL solicitaron formalmente a la FIFA que suspendiera la prohibición mientras se estudiaba a fondo la cuestión (20). No había cumplido un mes la controvertida medida cuando, el 27 de junio de 2007, la FIFA anunció en un comunicado de prensa que había decidido reducir la severidad de su prohibición y que, a partir de entonces, el límite máximo al que se podrían jugar partidos internacionales no sería 2500 msnm sino $3000 \mathrm{msnm}$. La presión ejercida por la opinión pública, por los gobernantes de los países afectados y por la CONMEBOL había surtido efecto; de hecho, la FIFA había tenido muy en cuenta que la CONMEBOL podría bloquear la prohibición en los países bajo su égida y que no convenía en absoluto generar semejante cisma al interior 
del cuerpo directivo del balompié mundial. Incluso los representantes ante la CONMEBOL de Brasil y Argentina, los países que habían dado inicio al alboroto, estaban en desacuerdo con la medida de la FIFA (21).

La nueva medida ponía a salvo El Campín de Bogotá, el Olímpico Atahualpa y el Casa Blanca de Quito y otros estadios con posibilidades de juegos internacionales como el Félix Capriles de Cochabamba, Bolivia, a $2579 \mathrm{msnm}$ (sede de los equipos Club Aurora y Club Deportivo Jorge Wilstermann), el estadio Olímpico Patria de Sucre, Bolivia, a $2.817 \mathrm{msnm}$ (sede del equipo Club Deportivo Universitario San Francisco Xavier) y el estadio Nemesio Díez de Toluca; pero seguía dejando por fuera de toda posibilidad los dos estadios de La Paz, el Hernando Siles y el Rafael Mendoza Castellón, además de otros estadios suramericanos con posibilidades técnicas de albergar partidos internacionales: el estadio Mario Mercado de Potosí, Bolivia, a 3895 msnm (sede los equipos Real Potosí y Club Atlético Nacional Potosí); el estadio Jesús Bermúdez de Oruro, Bolivia, a 3727 msnm (sede del Club San José) y el estadio Inca Garcilaso de la Vega de Cuzco, Perú, a 3362 msnm (sede del Club Cienciano).

Algunos de los estadios a mayor altitud en el mundo, como el estadio Daniel Alcides Carrión de Cerro de Pasco, Perú, a $4336 \mathrm{msnm}$ (sede del equipo de fútbol profesional Unión Minas); el estadio Enrique Torres Belón de Puno, Perú, a 3868 msnm (sede del Club Deportivo Alfonso Ugarte); el estadio Huancayo de la ciudad de Huancayo, también en Perú, a 3256 msnm (sede del Deportivo Wanca); y el estadio Rosas Pampa de Huaraz, Perú, a 3039 msnm (sede del Sport Áncash), aunque en teoría estaban cobijados por la prohibición habían quedado excluidos de antemano por no cumplir con el requisito mínimo para partidos internacionales de tener asientos para al menos 30000 espectadores (12).

El propio Evo Morales hizo suya la causa de recuperar los partidos de fútbol internacional para los estadios situados en las alturas y consiguió personalmente de Sepp Blatter la promesa de que La Paz "sería una excepción" y la FIFA permitiría que tuviesen lugar allí partidos internacionales (15). Al día siguiente la FIFA anunció que en el estadio Hernando Siles, se podrían seguir realizando los partidos de la eliminatoria a la Copa Mundial de Fútbol 2010 durante dos años más, lo que daba a entender que para el futuro próximo Bolivia debería tener un estadio de talla internacional a más baja altura (22).

Con motivo de la reunión de la CONMEBOL en Paraguay, los miembros de su Comité de Medicina Deportiva aseguraron, en contra de los argumentos del Comité de Medicina Deportiva de la FIFA, que no existía ningún riesgo para la salud de los deportistas si antes del partido se garantizaba un periodo de aclimatación para el equipo visitante (15) y agregaron que, mientras de un lado se exageraban los riesgos para la salud y las desventajas del juego en las alturas para los equipos no aclimatados, por el otro apenas sí se mencionaban los riesgos y las desventajas que supone para los equipos aclimatados a grandes alturas jugar en tierras bajas, en condiciones de temperatura y humedad del aire a las que no se encuentran adaptados sus jugadores (15).

Muchos expertos estuvieron de acuerdo en que no había un riesgo grave para la salud de los deportistas de élite no aclimatados que iban a jugar en la altura, pero mantuvieron su opinión de que existía una enorme desventaja para el equipo visitante. El Dr. Wilfried Kindermann, por ejemplo, ex jefe médico del Mundial de Fútbol de Alemania 2006 y de la Copa Confederaciones 2005, miembro de la Comisión Médica de la UEFA y director médico del equipo alemán que iría a las Olimpiadas de Beijing en el 2008, insistió, hablando para la Deutsche Welle (DW: la cadena de comunicaciones -radio, televisión, internet- de Alemania para el extranjero), en mantener el límite en $2500 \mathrm{msnm}$ : "Desde el punto de vista de la salud, los partidos llevados a cabo a más de 2500 metros de altura no representan ningún riesgo serio para los jugadores que se encuentran en buenas condiciones físicas; la vida de los deportistas no corre peligro a pesar de los malestares que ello ocasiona. Pero ese no es el punto clave. Lo decisivo es darle a la competencia un marco de igualdad que no existe si el rival sufre de mareos, náuseas y se fatiga más rápido por la falta de oxígeno" (23). Dejando a un lado, por ahora, su opinión sobre el "marco de igualdad", la declaración del Dr. Kindermann permite situar la discusión, desde el punto de vista científico, en un contexto más preciso: es posible que jugar fútbol (o practicar cualquier deporte) en la altura (o incluso a nivel del mar) conlleve riesgos no detectados para la salud de la población general en la que habría, por ejemplo, personas jóvenes sin evaluación médica previa a la práctica del deporte (24) (25), propensas a un síndrome de muerte súbita (con hipertrofia ventricular izquierda aún no detectada, cardiomiopatía hipertrófica, fibrosis ventricular izquierda, displasia arritmogénica ventricular derecha, anomalías congénitas de las arterias coronarias, miocarditis no detectada, síndromes de preexcitación tipo Wolff-Parkinson-White, síndromes de QT largo, canalopatías tipo Brugada, etc.) (26) (27) o personas no tan jóvenes con enfermedad coronaria no conocida (cuya manifestación será el evento coronario desencadenado por el esfuerzo deportivo) (28); se trata de que jugar fútbol en la altura no tiene riesgos para jugadores en buenas condiciones físicas, esto es bien entrenados, y en quienes una adecuada valoración médica previa ha permitido excluir enfermedades que podrían poner en riesgo sus vidas. Desde esta perspectiva, la aparición de Evo Morales y sus ministros en un juego callejero sería una especie de ruleta rusa en caso de haberlo hecho sin evaluación médica previa.

Sin embargo, para muchos expertos lo de la injusta desventaja o la ausencia del "marco de igualdad" no estaba muy claro. De hecho, análisis realizados en ese entonces mediante diversos modelos matemáticos mostraron que, al 
menos en los partidos de fútbol internacional en Sudamérica, no existía la supuesta ventaja de los equipos aclimatados a la altura y que la situación era, más bien, al contrario.

Patrick McSharry, por ejemplo, analizó los resultados de los 1460 partidos de fútbol jugados entre las selecciones nacionales en Sudamérica entre 1900 y 2004. Luego de descartar cualquier partido jugado en campo neutral (es decir, habiendo elegido sólo los encuentros en los que había equipo en casa y equipo visitante), estableció, además, un control para el desempeño general de cada equipo en cada época en consideración. Con base en ello, consiguió demostrar que, históricamente, los equipos residentes a bajas alturas jugando como visitantes a moderadas o grandes alturas habían ganado muchas más veces que los equipos aclimatados a moderadas o grandes alturas jugando como visitantes a bajas alturas (29). Demostró, además que, normalizando el número de goles marcados y concedidos en cada partido con respecto al número de goles marcados y concedidos históricamente por cada equipo individual, la probabilidad de un equipo residente en la altura de ganar como visitante jugando a la misma altura era de 0.5 (es decir, el equipo visitante tenía tantas posibilidades de ganar como de perder), jugando como local contra un visitante residente a nivel del mar la posibilidad de ganar era de 0.57 (el equipo local, en la altura, tenía una leve ventaja de ganar), pero jugando como visitante a nivel del mar contra un equipo residente allí la posibilidad de ganar era sólo de 0.27 (el equipo local, cercano a nivel del mar, tenía posibilidades abrumadoras de triunfar) (30). En 2009, un poco después de estos eventos, Rómulo Chumacero analizó los 252 partidos requeridos durante las eliminatorias sudamericanas a los mundiales de 1998, 2002 y 2006 y, "al contrario de lo que cree el común de la gente", encontró que la altura a la que se encuentra un estadio no parece ser un determinante sustancial en los resultados del partido, mientras que otros factores, como la temperatura o la humedad del ambiente o, incluso, la programación de los encuentros, sí lo son. Para Chumacero, aunque la altura fuera incluida como un determinante del resultado del partido, su importancia sería escasa desde el punto de vista cuantitativo: "si el concepto de desventaja injusta -afirma Chumacero- incluye cualquier factor diferente a la calidad del equipo que influya en el resultado del encuentro, entonces todos los equipos están jugando con una ventaja injusta cuando juegan en casa" (16). La ventaja a la que alude Chumacero ha sido reconocida desde hace mucho tiempo en muy diversos deportes y el análisis sobre su origen en el fútbol ha dado lugar a excelentes estudios en psicología del deporte (31).

Del 25 al 27 de octubre de 2007 el Comité de Medicina Deportiva de la FIFA y el Centro de Evaluación e Investigación Médica de la FIFA (FIFA Medical Assessment and Research Centre: F-MARC) organizaron en Zúrich una reunión de carácter científico a la que invitaron a 12 expertos internacionales en fisiología y medicina de las grandes alturas, a tres representantes de cada uno de los países con estadios a grandes alturas y a un representante de la Association de Footballeurs Professionels (FIFPro). El objetivo de la reunión era revisar y actualizar el conocimiento alcanzado hasta el momento con respecto a la práctica del fútbol a grandes alturas y lograr un consenso, lo más ajustado posible al conocimiento científico sobre el tema, que sirviera de base a las recomendaciones y guías que, sobre entrenamiento y juego del fútbol a diferentes alturas, daría el Comité de Medicina Deportiva de la FIFA. Dichas recomendaciones servirían, finalmente, para que el Comité Ejecutivo de la FIFA tomara una decisión informada al respecto.

Los participantes en dicha reunión científica llegaron a varias conclusiones. Estuvieron de acuerdo en que la altura sobre el nivel del mar (alta o baja) tiene impacto en el desempeño físico de los futbolistas; también estuvieron de acuerdo en que la altura sobre el nivel del mar (alta o baja) modifica el comportamiento aerodinámico del balón en movimiento después de patearlo (modificación que altera también la habilidad de los futbolistas para dirigir y controlar el balón); y, ante todo, estuvieron de acuerdo en que, a pesar de la extensa investigación presentada sobre actividad física y deporte a grandes alturas, la mayoría de las investigaciones científicas sobre el tema estaba dirigida a deportes individuales, por lo que sus conclusiones no siempre podían hacerse extensivas a deportes de equipo como el fútbol, aceptando con ello que en realidad no existía investigación sistemática sobre el desempeño de jugadores de futbol y menos aún sobre el desempeño de equipos de futbol en la altura. También estuvieron de acuerdo en que, además de la altura, era fundamental comprender el influjo que sobre el desempeño deportivo tienen otros factores medioambientales como el calor, el frío, la humedad relativa y la contaminación. Finalmente, con miras a las recomendaciones que harían al Comité Ejecutivo de la FIFA, acordaron clasificar los estadios de acuerdo con su altura en cinco categorías: cercanos a nivel del mar (de 0 a $500 \mathrm{msnm}$ ), a baja altura (de 501 a $2000 \mathrm{msnm}$ ), a moderada altura (de 2001 a $3000 \mathrm{msnm}$ ), a gran altura (de 3001 a $5500 \mathrm{msnm}$ ) y a extrema altura (por encima de $5501 \mathrm{msnm}$ ) (32).

De acuerdo con las conclusiones de este comité, los jugadores residentes a moderada y gran altura tendrían alguna ventaja desde el punto de vista del desempeño aerobio al descender a jugar a baja altura o cerca al nivel del mar (aunque aceptaron que algunas observaciones empíricas aun no muy bien estudiadas muestran que durante los primeros días su desempeño puede ser peor). Con respecto a la aerodinámica del balón y a la desventaja que pudiese tener para los futbolistas, estuvieron de acuerdo en que dicha desventaja está presente tanto para quienes ascienden a jugar a la altura como para quienes descienden a jugar más cerca a nivel del mar: en ambos casos el futbolista ha realizado su entrenamiento en un ambiente en el que el balón se comporta de manera diferente. 
En conclusión, lo único que pudieron recomendar fue que los jugadores residentes a nivel del mar tuvieran periodos de aclimatación de 3 a 5 días cuando fueran a jugar en estadios por encima de $1500 \mathrm{msnm}$, aclimatación de una a dos semanas cuando fueran a jugar a alturas moderadas (de 2001 a $3000 \mathrm{msnm}$ ) y aclimatación de mínimo dos semanas cuando fueran a jugar a grandes alturas (más de $3000 \mathrm{msnm}$ ) (32). Para este último caso, otros expertos recomendaron por entonces una semana de aclimatación en estadios de altura moderada antes de pasar otra semana en el estadio a gran altura en el que se realizaría el encuentro (30).

El 15 de diciembre de 2007 tuvo lugar en Tokio la última reunión del año del Comité Ejecutivo de la FIFA. Durante la misma se discutieron las conclusiones a las que el Comité de Medicina Deportiva había llegado durante el simposio de Zúrich junto con las recomendaciones derivadas de dichas conclusiones. Haciendo a un lado las conclusiones y las recomendaciones del Comité de Medicina Deportiva, el Comité Ejecutivo emitió un comunicado de fin de año, bastante escueto, en el que cambiaba de nuevo todo lo previamente acordado: "Hemos escuchado el informe del Dr. Michel D'Hooghe, director del Comité de Medicina Deportiva. A finales de octubre tuvo lugar un simposio sobre fútbol en condiciones extremas, y uno de los temas más importante fue el de los partidos jugados a gran altura. Hemos tomado una clara decisión determinando que no se jugará ningún partido internacional por encima de 2750 msnm sin la adecuada aclimatación" (33).

La nueva determinación del Comité Ejecutivo volvió a soliviantar los ánimos ya de por sí bastante caldeados de los países afectados. En este caso la más afectada seguía siendo Bolivia: ahora el límite no era $2500 \mathrm{msnm}$ ni tampoco $3000 \mathrm{msnm}$, sino $2750 \mathrm{msnm}$ ¿de dónde había surgido esa cifra? Con la excepción de los miembros del Comité Ejecutivo de la FIFA nadie lo sabía, pero sí quedaba claro que dichos miembros estaban dando palos de ciego buscando por donde salir del atolladero en el que ellos mismos se habían metido y arrastraban consigo a los miembros de un comité técnico-científico que declaraba sin cortapisas que había muchas cosas que no se sabían con respecto al fútbol de altura y que se requería más investigación antes de tener una repuesta clara.

Dos capitales, Bogotá y Quito, quedaban libradas de la prohibición con la nueva medida (aunque en Quito no se podrían jugar partidos internacionales en el estadio sede de la Selección de Fútbol del Ecuador, el Olímpico Atahualpa situado a $2779 \mathrm{msnm}$; sólo se podrían jugar en el Estadio Casa Blanca, a $2734 \mathrm{msnm}$ ). La capital de Bolivia seguía cobijada por la prohibición, aunque, se creía, Sepp Blatter honraría la promesa que seis meses antes le hiciera a Evo Morales de considerar a La Paz como una excepción. Los que no se librarían de la prohibición serían los estadios de capitales provinciales en Bolivia y Perú, con capacidad para encuentros internacionales, situados por encima de
2750 msnm, como el estadio Olímpico Patria de Sucre, Bolivia. El Nemesio Díez, el único estadio norteamericano inicialmente cobijado por la medida, seguiría también libre de la prohibición.

De nuevo, no se hicieron esperar las maniobras de lado y lado. Cada uno de los miembros de la CONMEBOL, en especial Bolivia, sentaron su voz de protesta y el Comité Ejecutivo de la FIFA prometió dedicar de manera exclusiva una próxima reunión a esclarecer de una vez por todas el asunto. El 14 de marzo de 2008 tuvo lugar la prometida reunión y vio la luz el pretendido esclarecimiento. En su nueva declaración el Comité Ejecutivo de la FIFA ratificó la prohibición de disputar partidos internacionales a más de 2750 msnm si los jugadores no habían tenido una semana de aclimatación previa al encuentro o dos semanas de aclimatacion si la altura era superior a $3000 \mathrm{msnm}$. Si se tiene en cuenta la reglamentación de la propia FIFA, según la cual los equipos de fútbol profesional tienen la obligación de dejar libres a sus jugadores para los partidos internacionales de las selecciones nacionales a las que pertenezcan 5 días antes de un encuentro, la ratificación de la prohibición por parte de la FIFA representaba, para Bolivia, la ruptura de la promesa que Blatter le había hecho a Evo Morales: ¿qué equipo profesional prestaría sus jugadores a las selecciones nacionales programadas para jugar en $\mathrm{La}$ Paz dos semanas antes del partido cuando su compromiso era darles permiso sólo 5 días antes? (34).

Era nada más y nada menos que una declaración de guerra. El 18 marzo de 2008, en el Estadio Hernando Siles de La Paz, el presidente de Bolivia Evo Morales y la estrella del fútbol argentino Diego Maradona, tomaron parte en un juego de fútbol de beneficencia (la entrada no se pagaba en dinero, sino en paquetes de arroz, pastas o harina) dirigido a recabar avituallamientos para las víctimas de las inundaciones en Bolivia. La programación del partido a la altura de La Paz y no en las tierras bajas bolivianas en donde habían ocurrido las inundaciones más graves (35) tenía una doble intención: además de conseguir fondos para los damnificados, el gobierno boliviano quería protestar por la "agresión contra los pueblos y la agresión contra el deporte" y demostrar que si personas mayores de 45 años, como Morales y Maradona, podían jugar sin problemas para la salud a la altura de La Paz, los futbolistas más jóvenes de los equipos internacionales tampoco tendrían ninguna dificultad (36). En ese partido, bajo los lemas "Debemos jugar donde nacimos" y "Jugar fútbol es una cuestión de actitud no de altitud", se enfrentaron antiguas estrellas del fútbol argentino, dirigidas por Maradona, y antiguas estrellas del fútbol boliviano, dirigidas por Morales. El equipo argentino, que venía del nivel del mar, ganó el encuentro por 7 goles contra 4 . Al final del partido Evo Morales declaró: "El fútbol une a los pueblos, pero esta decisión parece hecha para confrontarlos, la FIFA debe revisar esta ofensiva decisión" (36).

Declarada la guerra, Bolivia decidió apelar la "ofensiva decisión” del Comité Ejecutivo ante el plenum del Congreso 
de la FIFA a realizarse en Australia en mayo de 2008. Para su apelación buscó el apoyo de las federaciones de fútbol de África y de Europa, además de las de los otros países Sudamericanos (36) que -con la notable excepción de la del Brasil- ya habían firmado una declaración de apoyo a Bolivia.

El Congreso de la FIFA en Australia apoyó las aspiraciones de Bolivia. El 27 de mayo de 2008, un día antes de que se cumpliese el primer aniversario de la instauración de la prohibición, la FIFA suspendió toda restricción a los partidos internacionales a jugarse en las alturas. "Let us re-open the discussion" ("dejemos abierta de nuevo la discusión”) declaró Sepp Blatter después de la reunión del Comité Ejecutivo de la FIFA; y agregó que, al suspender la prohibición, la FIFA había tomado en cuenta la presión (lobbying) ejercida por las naciones sudamericanas: "El presidente del Comité de Medicina Deportiva desea considerar las amplias implicaciones de jugar fútbol bajo condiciones extremas, por lo que el Comité Ejecutivo ha suspendido provisionalmente la decisión del año pasado en contra de jugar en la altura" (37).

El asunto del fútbol de altura quedó, desde entonces, aparentemente resuelto, pero la verdad es que sigue latente y son muchos los jugadores de fútbol, los entrenadores, los directivos y, sobre todo, los hinchas por fuera de Bolivia, que siguen convencidos de que se debe hacer algo más con el fútbol de altura en lugar de permitir que Bolivia derrote impunemente en $\mathrm{La} \mathrm{Paz}$ a la Argentina por 2 a 0 aunque, aducen otros, la derrota se debió a que no jugó un tal Messi que se encontraba sancionado (38). Sin embargo, si fuese cierto que la altura es el factor más importante o uno de los que más afecta el resultado de un partido de fútbol, Bolivia habría sido varias veces el campeón mundial de fútbol desde que en 1925 se creó la Selección de Fútbol de Bolivia (es posible que algún día Bolivia sea campeón mundial de fútbol, pero no lo será por estar adaptado a la altura sino por jugar buen fútbol y eso incluye otras muchas variables).

Cuando la FIFA decidió tomar en sus manos los desencuentros que estaba generando entre algunos de sus miembros el fútbol en las alturas, se basó en premisas que parecían provenir de fuentes científicas o éticas. Con respecto a las fuentes científicas afirmaba la FIFA inicialmente que existía un riesgo medible desde el punto de vista médico para la salud de los deportistas no aclimatados que jugaban en las alturas (los contradictores afirmaban que también existía un riesgo medible desde el punto de vista médico para la salud de los deportistas no aclimatados que jugaban a elevadas temperaturas o en ambientes con humedad atmosférica mayor que las de su lugar de entrenamiento habitual). Desde el punto de vista ético, para la FIFA y para muchos otros no parece digno de encomio triunfar en un partido cuando la baja presión parcial de oxígeno en las alturas da lugar a condiciones fisiológicas adversas para el equipo contrario (pero los contradictores retoman el punto anterior: tampoco es digno de encomio triunfar en un partido cuando el exceso de temperatura o el exceso de humedad atmosférica da lugar a condiciones adversas para el equipo contrario). El punto es que la decisión de la FIFA de prohibir el fútbol internacional en las alturas, basada supuestamente en consideraciones científicas y éticas, dio lugar a conflictos políticos y, un año después, en una decisión política, la propia FIFA revirtió la medida.

Todas estas disputas políticas (en este caso el conflicto entre diversos grupos humanos sobre en qué lugares se debería o no jugar al fútbol) se hubieran evitado si, en lugar de intentar disfrazar un problema político con preguntas científicas (preguntas para las que la ciencia, además, aún no tiene respuesta definitiva o tiene sólo respuestas parciales) y dilemas éticos (dilemas que la gente irá resolviendo poco a poco mediante un sistema de contrapesos que termina por encontrar siempre su punto de justo equilibrio), se hubiese aceptado desde un comienzo que la queja planteada por los directivos del Flamengo y de otros equipos debía resolverse con acciones políticas. Cuando hablo de política me refiero a la Política, así con mayúsculas, en su concepción original: el conocimiento de los asuntos concernientes a la $\pi 0 \lambda ı \varsigma$ (polis: ciudad-estado) o, diríamos en la actualidad, a las comunidades humanas. Por tanto, sobraría insistir, pero no me resisto a hacerlo, en que al mencionar la Política, no me refiero a los tejemanejes, intríngulis y corruptelas, grandes y pequeños, que se suelen dar en el gobierno de un estado en las distintas esferas de los poderes ejecutivo, legislativo y judicial, tejemanejes que, por mala costumbre, seguimos llamando "política" aunque el diccionario de la Real Academia Española tiene un nombre preciso para ellos: politiquería (39).

Para Aristóteles, quien no creó el término, pero nos puso a pensar de manera sistemática en el asunto humano que la palabra designa, la Política era una forma de conocimiento

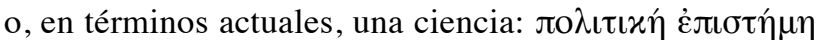
(politiké episteme: el conocimiento de los asuntos del estado) (40). Sin embargo, era ésta una ciencia especial, en la medida en que, para Aristóteles, el conocimiento que nos brinda la Política no es de carácter teórico; es decir, no se basa en la observación, como sí ocurre en las ciencias que llamamos naturales. Es necesario aclarar que para Aristó-

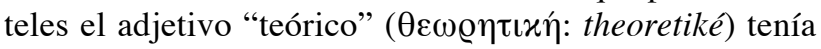
un sentido un poco diferente al que le damos en la actualidad: el adjetivo en cuestión se deriva del verbo $\theta \varepsilon \omega \varrho \varepsilon \omega$ (theoreo) que significa observar, mirar, contemplar; en griego clásico dicho verbo servía para señalar la acción realizada por los espectadores de las justas deportivas en el estadio olímpico, o la de los espectadores en el teatro, o la de los embajadores enviados a otro estado, o la de las comitivas enviadas a consultar el oráculo de Delfos, pero también, como no, la de quien hacía en un momento dado observaciones o consideraciones sobre sus propios contenidos mentales (41); en consecuencia, el adjetivo "teórico" venía a significar, nada más ni nada menos, que 
el sustantivo al que estaba calificando se basaba o requería o dependía de la observación.

Con base en la clasificación que hace del pensamiento discursivo, Aristóteles reconoce, de acuerdo con sus objetos y fines, tres tipos diferentes de ciencias o de cono-

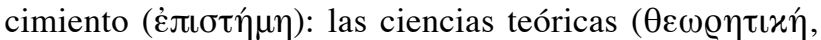
theoretiké), en las que el conocimiento está basado en la observación de los hechos y entre las que incluye, a manera de ejemplo, la física y las matemáticas; las ciencias pro-

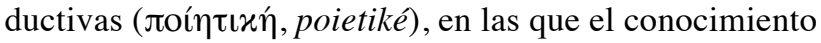
está dirigido a la producción tanto de cosas útiles como de cosas bellas y, en este caso, el conocimiento que requiere un ebanista para hacer un mueble queda justamente equiparado al de un poeta para escribir una tragedia; y las

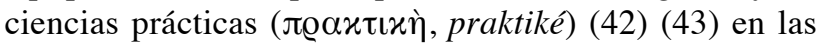
que el conocimiento está dirigido a la acción y entre las que incluye la Ética y la Política.

Para Aristóteles la Ética y la Política son actividades, $\pi \varrho \hat{\xi} \xi \iota \varsigma$ (praxis), basadas en metas, no en prescripciones, y las acciones humanas van, en uno y otro caso, dirigidas a resultados, a objetivos, en lugar de ir dirigidas a cumplir con reglas preestablecidas (como sí puede ocurrir en las ciencias productivas o en otras maneras de concebir la ética). Los conocimientos prácticos de la Ética y la Política no son, por ello, verdaderos o falsos, ni tampoco son útiles o inútiles (o bello o feos), sino que nos permiten actuar en el mundo de una cierta manera y dichas acciones podrán ser juzgadas, a posteriori, buenas o malas según si su efecto redunda o no en mejorar la "felicidad" (así, entre comillas) de cada persona (Ética) o de la comunidad (Política).

Las comillas en "felicidad" no son gratuitas, no debemos olvidar que para Aristóteles la "felicidad" no tiene nada que ver con el placer momentáneo, ni con la riqueza, ni con la fama y que, en realidad, el concepto de "felicidad" no puede, para él, desligarse de obrar de manera acorde con nuestras funciones o, dicho de otra manera, de obrar bien: por ello, todas nuestras acciones deben dirigirse a alcanzar la virtud ( $\alpha \varrho \varepsilon \tau \eta ́$ : areté), si así lo hacemos, seremos sin lugar a dudas "felices". Por su parte, la virtud consiste en el cumplimiento pleno de una función: la virtud de un constructor de barcos es hacer barcos fáciles de gobernar y difíciles de hundir, la virtud de un médico es conseguir la salud para sus pacientes, la virtud de los seres humanos consistiría, por tanto, en el cumplimiento pleno de nuestra función como seres humanos (de lo que nos hace ser lo que somos). Por ello, desde la perspectiva de la ética la "felicidad" consistiría en ejercer las virtudes (areté) esencialmente humanas derivadas del logos ( de la razón, de la capacidad de entender por qué debemos obrar de una manera y no de otra, con el fin de que nuestra vida dé los mejores frutos (44).

Desde la perspectiva del conocimiento práctico que es la Política (que para Aristóteles es la continuación de la Ética no ya en el ámbito individual sino en la comunidad de todos

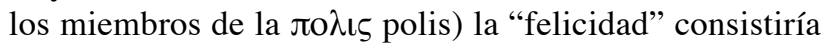

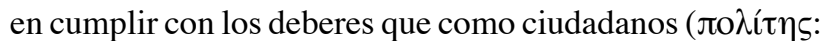
polites) tenemos los unos para con los otros con el fin de que cada uno pueda encontrar la mejor posibilidad de ser "feliz" (en el sentido de florecer y dar frutos) en la ло $\lambda \iota \varsigma$ (en la ciudad o, lo que para Aristóteles es lo mismo, en la comunidad humana).

El motivo de Aristóteles para situar la Ética y la Política en una categoría del conocimiento diferente a las categorías de la observación y de la habilidad necesaria para construir artefactos (o escribir un poema) es bien simple: los enunciados derivados del conocimiento obtenido a partir de la observación son o verdaderos o falsos, dependiendo de que el enunciado en cuestión sea o no acorde con la realidad; los enunciados derivados del conocimiento dirigido a la creación o a la factura de objetos no son ciertos o falsos, son instrucciones cuyo seguimiento da lugar o no a cosas útiles o bellas; pero con respecto a la Ética (y por ende a la Política, que es su continuación), el tipo de conocimiento que aportan estas dos ciencias no da lugar a enunciados que pueden ser ciertos o falsos o a enunciados-instrucciones que nos ayuden a crear o fabricar objetos que podrían o no ser bellos o útiles, los enunciados de la ética son bien diferentes y no estudiamos la Ética (y por ende la política) con el fin de conocer qué es la virtud o qué es el bien, sino con el fin de llegar a ser virtuosos y buenos, de lo contrario su estudio no aportaría ningún beneficio (45).

En el campo del conocimiento son, en el pensamiento aristotélico, tres las dicotomías en juego: la dicotomía verdadero-falso, perteneciente a la esfera del conocimiento observacional (teórico, diría Aristóteles); la dicotomía bello-feo (o útil-inútil), que pertenece a la esfera del conocimiento que podríamos llamar estético pero también artesanal o, incluso a mayor escala, industrial (creativo, lo llama Aristóteles); y, finalmente, la dicotomía bueno-malo, que constituye la síntesis del conocimiento ético-político (práctico, lo llama Aristóteles).

Desde la perspectiva del lenguaje la primera dicotomía sólo se puede resolver mediante el lenguaje descriptivo en tercera persona que se utiliza en las ciencias naturales, en la lógica y en las matemáticas: después de haber realizado la observación (o el experimento) o de haber llevado a cabo la demostración lógica o matemática, y sólo entonces, podremos afirmar si el enunciado inicial era verdadero o falso y, en este caso, el enunciado se ajusta a cómo es el mundo (46). La dicotomía bello-feo o útil-inútil sólo puede resolverse después de haber seguido paso a paso una serie de enunciadosinstrucciones en lenguaje imperativo o en voz pasiva (47): después de interactuar con el objeto producido, sea este una obra de arte o un objeto de uso, y sólo entonces, podremos afirmar que el objeto creado es bello o feo (o útil o inútil) y, en este caso, es el mundo (el objeto producido) el que debe ajustarse al enunciado. La dicotomía bueno-malo se declara en un lenguaje valorativo, inadmisible en las ciencias, que incluye las palabras bueno o malo o expresiones imperativas ("honrarás padre y madre", "no matarás", son ejemplos pro- 
venientes de nuestro ascendiente judeo-cristiano muy claros al respecto, imperativos con los que, sin duda, hubiera estado de acuerdo Aristóteles) que incitan a obrar bien o prohíben obrar mal. En este caso, el de los enunciados en lenguaje valorativo, ni el mundo tiene que adaptarse al enunciado ni el anunciado al mundo: son las acciones humanas las que acogen o no las recomendaciones de conducta contenidas en el enunciado y en este caso, para dar sólo dos ejemplos de posibles aproximaciones a la moral, o bien la dicotomía bueno-malo está resuelta a priori con base en un código de conducta preestablecido (morales deontológicas) o bien se resuelve a posteriori con base en el análisis de la conducta en cuestión con respecto a su aporte a la consecución de un determinado fin (morales teleológicas, como es el caso de la ética aristotélica) (40).

Aunque desde el punto de vista lingüístico el lenguaje prescriptivo del conocimiento productivo es muy similar al lenguaje prescriptivo-evaluativo del conocimiento práctico, no hay ningún motivo para que estos dos tipos de conocimiento puedan confundirse pues, advierte Aristóteles, una cosa es la producción o la creación, basadas siempre en un arte o técnica ( $\tau \dot{\varepsilon} \chi v \eta$, techné), y otra muy diferente la acción (moral) precedida por una deliberación (moral) sobre cómo es que debemos vivir nuestra vida y qué acción determinada conviene (o no) a nuestros fines al interior de la comunidad (48).

Cada una de estas dicotomías lingüísticas, que en la actualidad correspondería resolver respectivamente, aunque las fronteras son burdas y variables, a las ciencias, las técnicas y la moral privada y pública, pertenecen a categorías muy diferentes y mezclarlas constituye un craso error. Sin embargo, en muchos casos nos empeñamos en enredarlas (el fútbol de altura es sólo un ejemplo) con la aviesa intención de sacar alguna ventaja de perdurar en el error. Una cosa es el lenguaje descriptivo de la ciencia y otra el lenguaje valorativo de la moral, una el lenguaje en tercera persona de las ciencias: "jugar fútbol en la altura si no se está aclimatado puede inducir hipoxemia, disnea, malestar, etc." y otra el lenguaje imperativo-evaluativo de la moral: "no jugarás fútbol por encima de $2500 \mathrm{msnm}$ " o "jugar fútbol por encima de $2500 \mathrm{msnm}$ es malo". El error denunciado por Hume de derivar de un "es" un "debe", apodado por los filósofos analíticos del siglo XX "Falacia Naturalista", hace derivar de la dicotomía verdadero-falso (que es resuelta por la lógica o la investigación científica) conclusiones con respecto a la dicotomía bueno-malo que no tienen nada que ver ni con las deducciones de la lógica ni con las inducciones de la ciencia sobre los hechos del mundo (49), en realidad tienen que ver con qué decisiones o qué acciones consideramos mejores para construir nuestra vida (lo cual no quita que queramos a veces construir nuestra vida sobre bases científicas, o a veces no, como cuando elegimos que lo mejor para nosotros es practicar el boxeo o fumar a pesar de la evidencia científica sobre los daños que dichas actividades generan).
Pero los tiempos han cambiado. La Política, así con mayúsculas, que solía estar presente en las deliberaciones sobre los asuntos de la comunidad humana en tiempos de la Grecia Clásica ya no es lo que era y asistimos en nuestra época a un espectáculo lamentable que podríamos llamar política, así con minúsculas, para no tener que emplear el término bastante peyorativo de politiquería. Los tiempos han cambiado: el Político de aquel entonces sería en la actualidad más bien un Estadista pero, a decir verdad, bastante bien pocos de los políticos actuales lo son.

Platón había intentado definir qué era un Político antes que Aristóteles. Para llegar a su definición utilizó como estrategia la tesis de que la diferencia entre un monarca

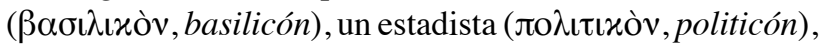

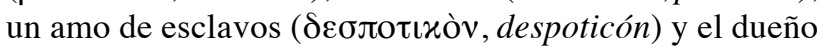
de una casa o hacienda (oixovouıxòv, oiconomicón) no era sino cuantitativa: una misma persona que hubiese desempeñado estos cuatro oficios a lo largo de su vida habría hecho siempre exactamente lo mismo y la única diferencia en cada caso habría sido el número de personas que tenía bajo su gobierno (50). Tanto era así, afirma Platón, que no habría una ciencia para cada uno de dichos oficios ("ciencia monárquica", "ciencia política" o "ciencia administrativa") sino una única ciencia cuyo nombre no importaba (51). En El Político Platón añadió a este argumento su definición de ser humano como "bípedo implume" (que más bien parece un chiste y que supo aprovechar muy bien Diógenes el cínico) (52) para poder culminar con ello en la sandez de que un político es un "pastor de hombres" (53). Aristóteles, sin mencionar a Platón, da inicio a su Política negando de manera tajante la equivalencia entre los cuatro oficios relacionados con gobernar ya mencionados y demuestra que existen diferencias esenciales entre ellos, no sólo en cuanto al número de gobernados (54).

Con el tiempo, sin embargo, siglos después de Platón y de Aristóteles, los oficios cambiaron; el cambio del Político al político fue sólo uno de tantos cambios nefastos. Aristóteles no tuvo en cuenta (no podía saberlo inmerso como estaba en una sociedad cuyo sistema de producción de bienes se basaba en la esclavitud), que, en un sistema de producción de bienes basado en la acumulación de capital, el oiconomicón y el despoticón terminarían por fusionarse en un único personaje (the capitalist, lo llamó David Ricardo) (55) para quien hasta el trabajo constituye una mercancía y cuyo poder llegaría a ser mayor que el del politicón y que el del basilicón, pues tiene en sus manos la posibilidad de quitar y poner a su antojo marionetas y títeres en puestos claves de la dirección del estado de acuerdo con sus intereses.

Aristóteles llegó a pensar, error de errores, que su ciencia le daría las herramientas al estadista, al Político, para garantizar la "felicidad" de los habitantes de la polis; nunca imaginó que esa misma ciencia, que ese conocimiento, servían y servirían en realidad a otras fuerzas, las económicas (derivadas de la hipertrofia de su oiconomicón al interior 
de sistemas de producción más fértiles para su gestión) para manejar a conveniencia, a veces abiertamente pero otras de manera subrepticia, el poder dentro del estado. Lo que sí dejó en claro Aristóteles fue que el poder no estaría en manos del sabio ni del filósofo a pesar de la pretensión de Platón de que en la utópica K $\alpha \lambda \lambda \eta ́$ ло ciudad bella), su ciudad ideal en el diálogo La República

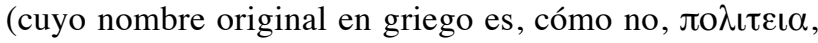
Politeia), los filósofos, dada su sabiduría, deberían ser los legítimos gobernantes (56).

En conclusión, los dilemas planteados por el fútbol de altura dieron lugar a una serie de disquisiciones científicas y éticas que seguramente son muy útiles al interior de las narrativas que sustentan el entramado social y nuestra noción de pertenencia a una cierta comunidad, pero un problema que inicialmente era Político, terminó travestido de problema científico y de interrogante ético (pues en cierto aspecto el problema parecían tener que ver con la justicia o la injusticia de algunos resultados de encuentros deportivos a partir de consideraciones estrictamente fisiológicas y éticas) para, finalmente resolverse desde la política (así, con minúsculas) a partir de una serie de presiones determinadas por factores económicos.

El ejemplo del fútbol de altura permite aclarar quién determina en última instancia al interior de una comunidad las decisiones que tienen que ver con la colectividad. Aunque en apariencia los políticos (algunos estadistas), los científicos, los directivos, los futbolistas y hasta los hinchas de a pie, estaban dando la batalla de uno y otro lado, al final la decisión no fue determinada por ninguno de ellos sino por quienes hacen que el negocio del fútbol profesional sea posible: inversionistas de capital; los mismos que apuestan parte de su peculio al "fichaje" (esa manera contemporánea de esclavitud que nadie entiende, pero todo el mundo acepta como normal) de una promesa del fútbol y terminan por ser "dueños" de un jugador o de un equipo, o invierten en el negocio del fabricante de balones y ropa deportiva, o en las cadenas televisivas que transmitirán los partidos, o en las cadenas hoteleras que alojarán a los hinchas, o en las empresas de ingeniería que construyen los estadios, hasta en las fábricas de gaseosas o de papas fritas que anuncian sus productos en el fútbol televisado, en la radio deportiva o en las pancartas de los estadios. Podemos estar seguros de que ninguno de los inversionistas de capital mencionados (y muchos otros que, directa o indirectamente, tienen que ver con el negocio del fútbol y que no alcanzaría a enumerar) aceptaría acabar con el fútbol en las ciudades de altura "porque da ventajas a los de casa" sabiendo que con ello se reducirían los réditos que deberían retornar de su inversión de capital.

No es infrecuente que una pregunta de origen político pueda obtener respuesta desde la ciencia ni tampoco es infrecuente que la política haga preguntas a la ciencia. De todas maneras, sin embargo, las acciones derivadas (o no) de las respuestas científicas a esas preguntas serán acciones políticas. Como en el caso del fútbol de altura, hay respuestas científicas a preguntas políticas (que la política acepte esa guía o no, es ya otro asunto) y hay acciones políticas ante respuestas de la ciencia a preguntas científicas (qué tan bien hechas hayan sido las preguntas, también está por verse). Pero, en ocasiones, se da el fenómeno contrario: no es la ciencia la que da respuesta a una pregunta política con el fin de servir de guía a los políticos, sino los políticos los que arrastran a la ciencia a dar respuestas políticas con ropaje de respuestas científicas, con lo que la ciencia deja de ser ciencia para transformarse en ideología. Algunas "investigaciones" relacionadas con el fútbol de altura siguen este derrotero, sin que podamos olvidar que, detrás de los determinantes políticos de una acción se encuentran siempre determinantes económicos.

En Colombia hace poco Colciencias, que es al quehacer científico de nuestro país como la FIFA para el balompié profesional mundial, quiso regular de manera diferente, previa concienzuda evaluación, la manera en que los investigadores científicos publican su producción del conocimiento en las publicaciones periódicas científicas que, valga lo pedestre de la comparación, vendrían a ser como los estadios en los que los investigadores se juegan su investigación y su carrera como científicos.

Para continuar, es necesario llover sobre mojado y agregar que, para que una investigación científica reciba el aval de la comunidad científica, es indispensable que aquellos miembros de dicha comunidad con conocimientos específicos en el área de las ciencias a la que atañe la investigación en cuestión, tengan pleno acceso a una descripción objetiva en lenguaje descriptivo de tercera persona que dé cuenta de todo el proceso de la investigación: desde cuáles fueron sus antecedentes hasta cuáles fueron los resultados observados, pasando obviamente por cuál fue la pregunta (hipótesis) científica que se buscaba verificar o falsar, cuáles los materiales (sujetos) de investigación, cuáles los métodos con los que se actuó sobre dichos materiales, para llegar, finalmente, a una disquisición alrededor de dichos resultados tratando de entroncarlos con los conocimientos previos, estableciendo de qué manera se integran al resto del conocimiento científico, dependiendo de la evaluación de los científicos expertos en el tema, o de qué manera refutan un área previamente considerada una verdad científica que, posiblemente de allí en adelante, dependiendo otra vez de la evaluación de los científicos expertos en el tema, ya no lo será más. Todo lo que antecede responde a la denominación de informe científico que, en su forma más depurada, perfeccionada a lo largo de varios siglos, corresponde a lo que en castellano denominamos artículo científico o trabajo científico, y que en inglés se conoce como scholarly paper, scientific paper o simplemente paper. Los expertos en el tema, por tanto, no deben sólo tener acceso al informe científico en su forma de artículo científico o paper sino que, además, deben evaluarlo, discutirlo, tratar de reproducir la investigación o el expe- 
rimento descritos e intentar refutar sus resultados de todas las maneras posibles, hasta que no quede duda de que el trabajo en cuestión tiene los merecimientos suficientes para hacer parte del corpus de la ciencia, caso en el cual se considera validado. Pero nada de esto ocurrirá, por excelente que haya sido su factura y por contundentes que hayan sido sus resultados y por preciso y detallado que haya sido el informe científico que da cuenta de estos hechos, si la investigación científica permanece oculta en los anaqueles del laboratorio de investigación o en el disco duro del computador del investigador principal. Las publicaciones periódicas científicas, independientemente del medio mediante el cual lleguen a la comunidad científica (revistas en papel, revistas electrónicas, video papers, etc.), cumplen con esa modesta pero indispensable función: presentar los trabajos de investigación de los científicos a otros científicos (sus pares, sus iguales) para que se pueda dar esa parte fundamental en el desarrollo del conocimiento que es la discusión, el libre examen.

Obviamente, no toda publicación periódica es una publicación periódica científica. No basta con decirlo, es necesario demostrarlo. Acta Médica Colombiana no es una publicación periódica científica porque el editor o el comité editorial de la misma lo afirmemos. Existen cuerpos reguladores que se encargan de definir cuáles publicaciones periódicas merecen el calificativo de científicas y cuáles no. Colciencias detenta en Colombia el poder de ser dicho cuerpo regulador y lo hace admitiendo o no una publicación periódica específica al grupo de publicaciones periódicas científicas, previa concienzuda evaluación como antes se dijo. Las publicaciones periódicas aceptadas como publicaciones periódicas científicas ingresan a través del Servicio de Indexación de Colciencias, Publindex, a la base de datos Publindex (57) en donde, además, son clasificadas en categorías (A1, A2, $\mathrm{B}, \mathrm{C}$ ) dependiendo de su relevancia como publicaciones periódicas científicas. Lo cual no significa que existan unas publicaciones periódicas científicas más científicas que otras, sino que existen algunas que tienen una mayor capacidad de difusión que otras (cómo medir esa capacidad de difusión es otro asunto del que no me voy a ocupar aquí, de ello se encargan: una ciencia, la cienciometría, y una técnica, la bibliometría).

Inicialmente tuvimos muchos la impresión, con base en el carácter científico con el que fue realizada la mencionada previa concienzuda evaluación (en la que, cómo no, la cienciometría y la bibliometría desempeñaron un importante papel), que las decisiones subsiguientes derivadas de ella tendrían un carácter igualmente científico. Olvidábamos, quienes así pensamos, que las acciones no son científicas; toda acción, toda praxis, ya lo dijo Aristóteles, es Política/política en el sentido de que genera modificaciones en la comunidad, en este caso en la comunidad científica, específicamente en la de las publicaciones periódicas científicas, pero con repercusiones en toda la comunidad científica y, claro, de manera directa e indirecta, en la comunidad en general.

Las evaluaciones poseen un aspecto científico inicial: se toman unos determinados sujetos, se averiguan ciertos datos de los mismos, se les aplican ciertos instrumentos o se realizan de manera directa ciertas mediciones sobre ellos y se obtienen unos determinados resultados. Para el caso de las publicaciones periódicas científicas, digamos, la etapa científica de una evaluación da lugar a una lista cruda de datos, un listado de todas las publicaciones periódicas científicas colombianas con sus características: quién es el editor, quiénes los miembros del comité editorial, cuántas veces al año se publica un número, cuántos artículos científicos evaluados por pares (peer reviewed) se publican en cada número, cuántas citaciones reciben esos artículos por parte de otros investigadores en otros artículos. Este último punto se considera fundamental pues cuando un artículo publicado en una publicación periódica científica es citado por otro autor en otro artículo queda claro que la publicación del primer artículo fue pertinente: alguien leyó el informe científico hecho público en el artículo, lo evaluó, le pareció de interés para su trabajo y utilizó sus resultados para, parapetado en ellos, realizar su propia investigación, avanzando un paso más el conocimiento científico. Si un artículo publicado en una publicación periódica científica recibe no una sino muchas citaciones en un periodo de tiempo definido, es indudable que ha tenido un impacto importante en el desarrollo del conocimiento.

Si los artículos publicados en un periodo específico se ordenan de manera decreciente con respecto a las citaciones que tuvieron en los artículos publicados en un periodo subsiguiente tendremos un rango de artículos que va desde algunos que han recibido muy pocas o ninguna citación hasta otros que han recibido el máximo de citaciones. Igual podemos hacer con las publicaciones periódicas científicas: establecemos un rango haciendo un listado de ellas ordenándolas de acuerdo con el número de citaciones que los artículos publicados en ellas han obtenido en un periodo determinado.

Nuestra investigación científica con respecto a las publicaciones periódicas científicas puede extenderse incluso mucho más: establecer si reciben más citaciones aquellas cuyo editor pertenece a una institución académica versus aquellas cuyo editor es un miembro de una cierta agremiación de científicos; o si reciben más citaciones las que se publican más veces por año que las que salen a la luz pública de manera más esporádica; o si reciben más citas las que son publicadas en chino mandarín que las que son publicadas en castellano o en inglés; etc. Se pueden aplicar también diversas herramientas bibliométricas (el índice de Hirsch, el factor de impacto, el SCImago Journal Rank -SJR- el Source Normalized Impact per Paper-SNIP-, el CiteScore o inventar herramientas nuevas con utilidades diferentes) y crear con base en ellas diferentes rangos de artículos, de autores, de revistas, de instituciones, etc. puesto 
que para la cienciometría no hay un límite preestablecido en cuanto a lo que podemos llegar a saber y entender con respecto a la difusión de la producción del conocimiento. Pero hasta aquí estamos utilizando el lenguaje de la ciencia: neutral, en tercera persona, descriptivo y podemos hacer al respecto enunciados ("la publicación x recibe más citaciones que la publicación y", "el Profesor N ha sido citado más veces en los últimos dos años que el Doctor M"), enunciados que, científicamente, serán verdaderos o falsos dependiendo de los hechos, no de los valores.

Pero también es posible construir, sobre estos mismos hechos, enunciados expresados en el lenguaje valorativo que se utiliza en la ética y en la política, en lugar de hacerlo con el lenguaje científico. El asunto, llegados a este punto, es que los enunciados político/morales determinan acciones, son prácticos, como diría Aristóteles, pues pertenecen a la clase de enunciados que, como nos enseñó John L. Austin (58), "hacen cosas con palabras", o, dicho de otra manera, son palabras que son acciones en sí mismas: cuando digo "te prometo que..." no sólo estoy diciendo algo sino que estoy haciéndolo, estoy diciendo te prometo y estoy prometiendo algo; cuando un hombre (o una mujer) dice "acepto" en una ceremonia de matrimonio frente al notario y al lado de quien a partir de ese mismo momento es ya su esposa (o su esposo), no sólo está diciendo "acepto", sino que lo está haciendo, está aceptándola (aceptándolo) y está aceptando que a partir de ese momento su vida cambia, pues esa palabra "acepto" hace cosas, cambia el mundo, hará que las instituciones funcionen en adelante de una manera diferente para él (para ella); para ponerlo en tono dramático, y este es sólo uno de innumerables ejemplos de que ese "acepto" cambia el mundo: por el hecho de haber dicho "acepto", si la persona que dice "acepto" muere en el instante siguiente, sus herederos serán diferentes a si hubiese muerto antes de decirlo.

Igual sucede cuando se construyen clasificaciones evaluativas cuyo lenguaje ya no es científico sino valorativo: "esta publicación es mejor que esta otra" (como quien dice "esta es buena, esta es mala", en lugar de mantener el lenguaje científico y decir "la publicación x recibe más citaciones que la publicación y"), "este artículo se encuentra en el cuartil de los mejores" "“está entre el $25 \%$ de los que reciben más citaciones", diríamos en lenguaje científico). Como vemos, con el sólo hecho de que el lenguaje científico sea trastocado en lenguaje valorativo un "es" se transforma en "debe" (una forma clara de llevar a la práctica la Falacia Naturalista). Si bien el enunciado: "las publicaciones periódicas científicas colombianas son asî" sería el enunciado científico de la primera parte de una evaluación de dichas publicaciones, el enunciado de la segunda parte de la evaluación, en el lenguaje evaluativo, adquiere un carácter valorativo que antes no tenía: "Las publicaciones periódicas científicas colombianas deben ser asî". Y, como vimos, las evaluaciones político-morales, al igual que las palabras de Austin que "hacen cosas", cambian el mundo.
De acuerdo con el Decreto 1279 del 19 de junio de 2002 "por el cual se establece el régimen salarial y prestacional de los docentes de las Universidades Estatales", el investigador cuyo trabajo de investigación es aceptado para ser publicado en una publicación científica periódica recibe un determinado número de puntos para ser sumados como puntaje de productividad académica con los puntajes dados por sus títulos correspondientes a estudios universitarios, su categoría dentro del escalafón docente y su experiencia calificada. Dicha sumatoria se utiliza tanto al ingresar a la carrera docente, como al reingresar a la misma o como parte de la evaluación periódica de la productividad con el fin de asignar el salario y las bonificaciones salariales a que haya lugar. Es por ello que al cambiar el lenguaje científico de la evaluación de una publicación científica periódica por un lenguaje valorativo y en lugar de decir "la publicación $\mathrm{x}$ recibe menos citaciones que la publicación y pero más que la publicación z", decimos en un lenguaje valorativo "la publicación x se encuentra en la categoría A2" hacemos cosas con palabras, modificamos el mundo. Y lo modificamos porque si en la evaluación siguiente en lugar de decir "la publicación x se encuentra en la categoría A2", decimos de la misma publicación "la publicación x se encuentra en la categoría C", el puntaje asignado al autor de una investigación publicada en la publicación $\mathrm{x}$ ya no será de 12 puntos sino de 3 puntos (los puntajes de acuerdo con el Decreto 1279 son 15 puntos por trabajos publicados en revistas de categoría A1, 12 puntos por trabajos publicados en revistas de categoría $\mathrm{A} 2,8$ puntos por trabajos publicados en revistas de categoría $\mathrm{B}$ y 3 puntos por trabajos publicados en revistas de categoría C) (59).

El año pasado Colciencias convocó a las publicaciones periódicas científicas de Colombia a ser indexadas en $\mathrm{Pu}$ blindex (Convocatoria No.768 de 2016 para la Indexación de Revistas) (60); en dicha convocatoria se establecían las diferentes etapas del proceso: una primera etapa, llamada de diagnóstico, que se abriría el 16 de agosto de 2016 y se cerraría el 14 de octubre de 2016 durante la cual los editores registrarían la información pertinente ante Colciencias y una segunda etapa, llamada de clasificación oficial, que se abriría el 2 de diciembre de 2016 y se cerraría el 31 de mayo de 2017 durante la cual Colciencias estudiaría la información aportada por los editores, corroboraría su exactitud examinado directamente las publicaciones en cuestión y analizando de manera comparativa el impacto de dichas publicaciones mediante diversas herramientas bibliométricas, como la presencia o no de la publicación en Bases bibliográficas con comité científico de selección (BBCS) como la Web of Science (WoS) o Scopus y rango actual en los Índices Bibliográficos Citacionales clasificando la publicación con base en el factor de impacto en el Journal of Citation Reports (JCR) y el SCImago Journal \& Country Rank (SJR) junto con otros indicadores de impacto citacional como el índice de Hirsch. Los resultados se harían públicos el 15 septiembre de 2017. Las fechas límite 
se cumplieron a la perfección y entre la fecha de cierre de la etapa de clasificación oficial y la fecha de publicación de los resultados hubo tiempo para que las publicaciones periódicas que lo desearan aclararan parte de la información con miras a hacer más precisa su clasificación en los resultados. La publicación de éstos se llevó a cabo en la fecha prevista mediante la resolución 0929 de 2017 (61).

A la etapa de diagnóstico se presentaron 627 publicaciones periódicas, de las cuales fueron avaladas 583. Las publicaciones avaladas tenían, desde el punto de vista de la cienciometría, las características para ser consideradas como pertenecientes al género de las publicaciones periódicas científicas y podían pasar a la siguiente etapa. Fueron rechazadas 44 publicaciones periódicas que, dadas sus características, no podían ser consideradas desde el punto de vista de la cienciometría como publicaciones periódicas científicas. Las 583 publicaciones avaladas fueron examinadas mediante las diversas herramientas bibliométricas ya mencionadas. A las revistas no indexadas en ninguno de los dos IBC, se les midió el impacto citacional con base en el índice $\mathrm{H}$, cuya naturaleza y explicación fue parte de otro editorial en esta revista (62). Hasta aquí todo iba muy bien: se trataba de establecer los hechos mediante metodología científica. El problema comienza cuando se tienen los datos sobre esos hechos y se transforman esos datos en un lenguaje valorativo. De las 583 publicaciones avaladas sólo fueron aceptadas 244 publicaciones, las 339 restantes simplemente no existen, no ingresan a Publindex porque no están indexadas en ningún IBC y su índice $\mathrm{H}$ las situaba en los dos últimos cuartiles de su categoría (que es más o menos igual que decir que entre mis 20 alumnos del semestre de Medicina Interna, de los cuales sólo 2 no alcanzaron los objetivos planeados y perdieron el semestre, decido más bien tomar las notas definitivas de todos, crear un rango de mayor a menor y declarar el semestre perdido para los 10 alumnos cuya nota se encuentra de la mediana hacia abajo en el rango de notas que he creado). Si esas publicaciones periódicas científicas no están en Publindex los trabajos científicos publicados en ellas no servirán ni para mejorar la categoría profesoral en una Universidad ni para mejorar o mantener la categoría de un grupo de investigación, es decir, en términos prácticos no existen, pero no existen porque, volviendo al punto anterior, $\mathrm{Col}$ ciencias ha hecho cosas con palabras al transformar un "es" en un "debe", al caer en la Falacia Naturalista de modificar el lenguaje científico inicial por lenguaje evaluativo que permite que las palabras hagan cosas.

De las 244 publicaciones periódicas científicas aceptadas en Publindex sólo una de ellas pertenece a la categoría A1 (en la convocatoria Publindex previa, realizada en 2014, había 29 publicaciones en esta categoría) (63), sólo hay 14 en la categoría A2 (en la convocatoria Publindex previa había 146 publicaciones en esta categoría), hay 104 publicaciones en la categoría B (en la convocatoria Publindex previa había 122) y 125 en la categoría C (en la convocatoria previa había 226). Acta Médica Colombiana ha sido clasificada en la categoría $\mathrm{C}$.

Desde el punto de vista científico seguimos buscando una respuesta precisa al problema planteado por el fútbol de altura: una ley o un conjunto de leyes de la naturaleza que permitan explicar retroactivamente los resultados de un partido de fútbol o predecirlos con base en variables medioambientales (cuyo verdadero impacto aún desconocemos). Pero, incluso cuando tengamos esa ley o ese conjunto de leyes, estaremos lejos de poder predecir el marcador de un partido debido a una serie de imponderables entre los cuáles el más importante es, sin duda, qué tan bueno es un equipo y qué tanta determinación y empeño ponga en ganar, cosas ambas que los científicos, a diferencia de la altura sobre el nivel del mar, no saben medir. Cuando las instituciones tratan de suplir esa falta de conocimiento con clasificaciones arbitrarias de carácter valorativo en lugar de mantener el lenguaje científico y admitir la presencia de vacíos en el conocimiento se afecta moralmente a muchas personas (aceptando que la moral es "lo que nos debemos los unos a los otros", como quiere Thomas Scanlon) (63) y se ponen en marcha hechos políticos como en el ejemplo del fútbol de altura. Exactamente lo mismo ocurre cuando Colciencias cambia el lenguaje científico de la cienciometría por el lenguaje valorativo de una clasificación como la de Publindex en la que, sin lugar a dudas, las clases que se muestran no son clases naturales.

Queda por verse, como en el caso del fútbol de altura, la conexión económica de todos estos cambios políticos, travestidos de investigación científica, en la indexación y clasificación de las publicaciones periódicas científicas colombianas. No es fácil encontrarla, pero existe... al releer la Política Nacional para Mejorar el Impacto de las Publicaciones Científicas Nacionales (64), el documento de Colciencias publicado en el año 2016 con el que se dio inicio a todo este barullo, encuentro que en él aparece mencionada en varias ocasiones la clasificación de áreas científicas según la Organización para la Cooperación y el Desarrollo Económicos (OCDE). ¿Por qué no se empleó, por poner sólo un ejemplo, la Nomenclatura Internacional de la Unesco para los campos de Ciencia y Tecnología?. La OCDE es una institución muy seria a la que Colombia pretende pertenecer en un futuro (su ingreso se encuentra en etapa de observación) y la OCDE es, además, una abanderada del libre comercio y de la globalización. Así que, atando cabos, es muy posible que el objetivo sea poner las publicaciones periódicas científicas colombianas en el mismo rango de las publicaciones internacionales de los países que pertenecen a la OCDE. No está mal, son acciones políticas que tendrán sus efectos seguramente bienvenidos por muchos en los campos de la industrialización y del comercio, pero ya en el editorial anterior mostré de qué manera un país como el nuestro, con sus propios problemas y sus propias necesidades humanas e investigativas, será transformado por la globalización de la investigación cien- 
tífica en un consumidor y no en un productor de ciencia, y quedará a un lado nuestra producción de conocimientos científicos (así éstos fuesen ciencia local, pero, de todas maneras, ciencia para nuestros acuciantes problemas).

\section{Referencias}

1. Anonimous. Real Potosí se durmió y dejó escapar una victoria. [Internet]. Agencia de Noticias FIDES. Potosí; 2007 [consultado el 17 de junio de 2017]. Disponible en: http://www.noticiasfides.com/deportes/real-potosi-se-durmio-ydejo-escapar-una-victoria-152304.

2. Anonimous. Flamengo vs. Real Potosí - Estadísticas del Partido [Internet]. ESPN. 2007 [consultado el 17 de junio de 2017]. Disponible en: http://www. espn.com.co/futbol/numeritos?juegoId=213142.

3. Anonymous. Nota Oficial - Maracanã- C.R do Flamengo - [Internet]. Clube de Regatas Do Flamengo. 2016 [consultado el 18 de junio de 2017]. Disponible en: http://www.flamengo.com.br/site/noticia/detalhe/24143/nota-oficial-maracana.

4. Anonimous. Ahora el estadio se llama Víctor Agustín Ugarte [Internet]. El Potosí. 2007 [consultado el 18 de junio de 2017]. Disponible en: http://nuestrapiza. lescigales.org/paginas/ugarte.htm.

5. Witzig R. Soccer at the Top of the World. In: The Global Art of Soccer. First Edition. New Orleans: CusiBoy Publishing; 2006: pp 323-33.

6. Anonymous. Real Potosí - Liga Boliviana [Internet]. Resultados Futbol.com. 2017 [consultado el 19 de junio de 2017]. Disponible en: http://www.resultadosfutbol.com/Real-Potosi.

7. Anonimous. World Stadiums [Internet]. 2017 [consultado el 20 de junio de 2017]. Disponible en http://www.worldstadiums.com/.

8. Anonimous. Elevationmap.net [Internet]. Worldwide elevation. 2017 [consultado el 20 de junio de 2017]. Disponible en: http://elevationmap.net/\#menu2.

9. Anonimous. Copa Libertadores: Flamengo no jugará más en altura [Internet]. El Mercurio On-Line. Santiago de Chile; 2007 [consultado el 21 de junio de 2017]. Disponible en: http:/www.emol.com/noticias/deportes/2007/02/15/246024/ copa-libertadores-flamengo-no-jugara-mas-en-altura.html.

10.Anonimous. Fifa bans high-altitude football [Internet]. BBC News. 2007 [consultado el 21 de junio de 2017]. Disponible en: http://news.bbc.co.uk/2/ hi/6697159.stm.

11. Anonimous. FIFA's Altitude Ban: Is Sepp Blatter High? [Internet]. The New York Times. 2007 [[consultado el 21 de junio de 2017]]. Disponible en: https://goal. blogs.nytimes.com/2007/06/28/fifas-altitude-ban-is-sepp-blatter-high/?_r=0.

12.FIFA. Football Stadiums Technical recommendations and requirements [Internet]. 4th ed. Dunne F (editor). Zurich: FIFA; 2007. pp 26-27. [consultado el 21 de junio de 2017] Disponible en: http://www.ksi.is/media/mannvirki/ FIFA_Football_Stadiums.pdf.

13. Iturrieta F. Soccer-Chile consider high altitude venue for World Cup qualifiers [Internet]. Reuters. 2014 [[consultado el 21 de junio de 2017]]. Disponible en: http://uk.reuters.com/article/soccer-chile-altitude-idUKL3N0S84KZ20141013.

14. Assemblée Nationale. Constitution de la République française [Internet]. Titre XII. Article 72-3. [consultado el 21 de junio de 2017]. Disponible en: http:// www.assemblee-nationale.fr/connaissance/constitution.asp\#titre_12.

15. Fernández-Quesada E. ¿Por qué juega Colombia en Barranquilla? [Internet]. ElTiempo. 2015. [consultado el 21 de junio de 2017]. Disponible en: http:// www.eltiempo.com/archivo/documento/CMS-16396881.

16.IGAC. Instituto Geográfico Agustín Codazzi [Internet]. Acerca del IGAC. 2017 [consultado el 21 de junio de 2017]. Disponible en: http://www.igac.gov.co/igac.

17. Anonimous. Por 53 metros Colombia no podrá jugar en Bogotá [Internet]. El Mercurio On-Line. 2007 [consultado el 21 de junio de 2017]. Disponible en: http://www.emol.com/noticias/deportes/2007/06/04/258080/por-53-metroscolombia-no-podra-jugar-en-bogota.html.

18. Anonimous. Bolivian leader kicks off [Internet]. BBC News. 2007 [consultado el 21 de junio de 2017]. Disponible en: http://news.bbc.co.uk/2/hi/americas/6704605.stm.

19. Anonimous. Evo Morales planta cara a la FIFA con un partido en La Paz [Internet]. El Mundo España. 2007 [consultado el 21 de junio de 2017]. Disponible en: http://www.elmundo.es/elmundodeporte/2007/05/30/futbol/1180557238.html.

20. Anonimous. S America urges Fifa to lift ban [Internet]. BBC News. 2007 [consultado el 21 de junio de 2017]. Disponible en: news.bbc.co.uk/2/hi/americas/6755555.stm.

21. Anonimous. Fifa relents on altitude ruling [Internet]. BBC News. 2007 [consultado el 21 de junio de 2017]. Disponible en: http://news.bbc.co.uk/sport2/ hi/football/6244512.stm.

22. Chumacero RA. Altitude or Hot Air? J Sports Econom 2009; 10(6): 619-38.

23. Martínez D. Médico del Mundial 2006 apoya la decisión de la FIFA [Internet]. Deutsche Welle. 2007 [consultado el 21 de junio de 2017]. Disponible en: http://www.dw.com/es/médico-del-mundial-2006-apoya-la-decisión-de-lafifa/a-2569658.

24.Corrado D, Pelliccia A, Bjørnstad HH, Vanhees L, Biffi A, Borjesson M, et al. Cardiovascular pre-participation screening of young competitive athletes for prevention of sudden death: proposal for a common European protocol. Eur Heart J [Internet]. 2005 Mar 1 [cited 2017 Nov 14];26(5):516-24. Disponible en: http://academic.oup.com/eurheartj/article/26/5/516/2888062/Cardiovascularpreparticipation-screening-of-young

25. Drezner JA, O FG, Harmon KG, Fields KB, Asplund CA, Asif IM, et al. AMSSM Position Statement on Cardiovascular Preparticipation Screening in Athletes: Current evidence, knowledge gaps, recommendations and future directions. Br J Sport Med 2017; 51: 153-67.

26. Finocchiaro G, Papadakis M, Robertus J-L, Dhutia H, Steriotis AK, Tome M, et al. Etiology of Sudden Death in Sports. J Am Coll Cardiol 2016; 67(18): 2108-15.

27. Bagnall RD, Weintraub RG, Ingles J, Duflou J, Yeates L, Lam L, et al. A Prospective Study of Sudden Cardiac Death among Children and Young Adults. N Engl J Med 2016; 374 (25): 2441-52.

28. Marijon E, Tafflet M, Celermajer DS, Dumas F, Perier M-C, Mustafic H, et al. Sports-related sudden death in the general population. Circulation 2011; 124 (6): 672-81.

29. McSharry PE. Effect of altitude on physiological performance: a statistical analysis using results of international football games. BMJ 2007; 335 (7633): 1278-81.

30.Gore CJ, McSharry PE, Hewitt AJ, Saunders P. Preparation for football competition at moderate to high altitude. Scand J Med Sci Sports 2008; 18 (Suppl 1): 85-95.

31. Waters A, Lovell G. An Examination of the Homefield Advantage in a Professional English Soccer Team from a Psychological Standpoint. Footb Stud 2002; 5 (1): 46-59.

32. Bärtsch P, Saltin B, Dvorak J. Consensus statement on playing football at different altitude. Scand J Med Sci Sports 2008; 18 (Suppl 1): 96-9.

33. Anonimous. Productive FIFA Executive Committee meeting [Internet]. FIFA COM. 2007 [consultado el 21 de junio de 2017]. Disponible en: http://www.fifa. $\mathrm{com} /$ about-fifa/news $/ \mathrm{y}=2007 / \mathrm{m}=12 /$ news=productive-fifa-executive-committeemeeting-661020.html.

34. Anonimous. La FIFA ratifica su veto a los estadios en altitud. El Mundo.es [Internet]. 2008 Mar 14 [consultado el 24 de junio de 2017]; Disponible en: http://www.elmundo.es/elmundodeporte/2008/03/14/futbol/1205530467.html.

35. Unidad Técnica Nacional de Información de la Tierra. Mapa de Áreas y Predios Afectados por la Inundación Provocada por el Fenómeno "La Niña 2007-2008." La Paz; 2008 [consultado el 24 de junio de 2017]; Disponible en: https://geo. gob.bo/geonetwork/srv/spa/resources.get?uuid=267151c3-7ac0-4e09-8ad86312d5113c9c\&fname=MEMORIA_TECNICA_DEL_MAPA_DE_INUNDACIONES_LA_NINA_2008.pdf\&access=private.

36. Schipani A. Maradona in Bolivia charity match [Internet]. BBC News. 2008 [consultado el 24 de junio de 2017]. Disponible en: http://news.bbc.co.uk/2/hi/ americas/7302020.stm.

37. Anonimous. FIFA levanta prohibición que impedía a Bolivia jugar en La Paz [Internet]. El Mercurio On Line. 2008 [consultado el 24 de junio de 2017]; Disponible en: http://www.emol.com/noticias/deportes/2008/05/27/305922/ fifa-levanta-prohibicion-que-impedia-a-bolivia-jugar-en-la-paz.html.

38. Vande-Rusten P. Argentina, sin Messi, cae ante Bolivia en la altura de La Paz [Internet]. El País. 2017 [consultado el 24 de junio de 2017]; Disponible en: http:// deportes.elpais.com/deportes/2017/03/28/actualidad/1490727974_766769.html.

39. Real Academia Española. Politiquear. En: Diccionario de la Lengua Española $23^{\mathrm{a}}$ ed. Espasa Libros; 2014: p 1749.

40. Aristóteles. Retórica. 1359 b. 6th ed. Tovar A, editor. Madrid: Centro de Estudios Políticos y Constitucionales; 2002. 22 p.

41. Liddell HG, Scott R, Jones HS, McKenzie R. $\theta \varepsilon \omega \varrho \varepsilon \omega$. Greek-English Lexicon 9th Edition. Oxford: Clarendon Press; 1940. [Internet] [consultado el 24 de junio de 2017]. Disponible en: http://stephanus.tlg.uci.edu/lsj/\#eid=49911\&context= 1 sj\&action=from-ref.

42.Aristóteles. Metafísica VI, 1, 1025b-1026a. Primera Ed. Calvo-Martínez T (Editor). Madrid: Editorial Gredos; 1994. pp 207-212.

43. Aristotle. The Organon. Volumen 2. Topica VI, 6, 145a14-17. Forster E (Editor). Cambridge, Massachusetts: Harvard University Press; 1960: pp 600-601.

44. Matijasevic E. Aliviar siempre. Acta Med Colomb 2011; 36 (1): 4-9.

45. Aristóteles. Ética a Nicómaco 1103b26-29. Octava Edición. Araújo M, Marías J (Editores). Madrid: Centro de Estudios Políticos y Constitucionales; 2002: p 20.

46. Guariglia O, Vidiella G. Breviario de Ética. Primera Edición. Buenos Aires: EDHASA; 2011: pp 27-35. 
47. Delin J. The Language of Instructions. In: The Language of Everyday Life: An Introduction. London: Sage Publications; 2000; pp 59-80.

48. Aristóteles. Ética a Nicómaco 1140a1-23. Octava Edición. Araújo M, Marías J (Editores). Madrid: Centro de Estudios Políticos y Constitucionales; 2002: pp 91-92.

49. Muguerza J. "Es" y "Debe": en torno a la falacia naturalista. En: La Razón sin Esperanza. Tercera edición. Madrid: Plaza y Valdés; 2009: pp 79-114.

50.Platón. Político 258d. En: Santacruz MI (Editor). Diálogos V: Parménides, Teeteto, Sofista, Político. Madrid: Editorial Gredos; 1988: pp 502-3.

51. Platón. Político 259b-259c. En: Santacruz MI (Editor). Diálogos V: Parménides, Teeteto, Sofista, Político. Madrid: Editorial Gredos; 1988: p 504.

52. Matijasevic E. El bipedo implume dependiente. Acta Médica Colomb 2014; 39 (2): 99-105

53. Platón. Político 261d. In: Santacruz MI, editor. Diálogos V: Parménides, Teeteto, Sofista, Político. Madrid: Editorial Gredos; 1988. p. 509.

54. Aristóteles. Política 1252a. Gómez-Robledo A (Editor). México: Universidad Nacional Autónoma de México; 2000: pp 1-2.

55. Ricardo D. Principles of Political Economy and Taxation. Kolthammer F (Editor). New York: Dover Publications; 2006: p 31.

56.Platón. La República 473d-473e. Primera Edición. Eggers-Lan C (Editor). Madrid: Editorial Gredos; 1986: pp 282-283.

57.Publindex [Internet]. Colciencias. 2017 [consultado el 24 de septiembre de
2017]. Disponible en: http://scienti.colciencias.gov.co:8084/publindex/.

58. Austin JL. How to do things with Words. Second Edition. Cambridge, Massachusetts: Harvard University Press; 1975: $176 \mathrm{pp}$.

59. Decreto 1279 de Junio 19 de 2002 [Internet]. Bogotá: Presidencia de la República de Colombia; 2002 [consultado el 24 de septiembre de 2017]; Disponible en: http://www.mineducacion.gov.co/1621/articles-86434_Archivo_pdf.pdf.

60. Colciencias. Convocatoria para Indexación de Revistas Científicas Colombianas Especializadas - Publindex [Internet]. 2016 [consultado el 24 de septiembre de 2017]. Disponible en: http://www.colciencias.gov.co/convocatorias/investigacion/convocatoria-para-indexacion-revistas-cientificas-colombianas.

61. Colciencias. Resolución 0929 de 2017 [Internet]. Publindex. 2017 [consultado el 24 de septiembre de 2017]. Disponible en: http://www.colciencias.gov.co/ sites/default/files/resolucion-0929-2017.pdf.

62. Matijasevic E. La aplicación del conocimiento. Acta Médica Colomb 2017; 42 (1): $1-11$

63. Colciencias. Índice Bibliográfico Nacional - IBN Publindex II Actualización 2014 [Internet]. Publindex. 2014 [consultado el 24 de septiembre de 2017]; Disponible en: http://scienti.colciencias.gov.co:8084/publindex/EnIbnPublindex/ buscador.do.

64. Colciencias. Política Nacional para Mejorar el Impacto de las Publicaciones Científicas Nacionales [Internet]. Bogotá; 2016 [consultado el 24 de septiembre de 2017]. Disponible en: http://www.colciencias.gov.co/sites/default/files/ upload/paginas/politica-publindex-colciencias.pdf. 